\title{
Secondary Traumatic Stress, Burnout, and Compassion Satisfaction Among Child Advocacy Interdisciplinary Team Members
}

\author{
Marlys Staudt \\ Mona Williams-Hayes
}

\begin{abstract}
Recent research has examined the stress and indirect trauma experienced by helping professionals who work with survivors of direct trauma, including interpersonal violence. Little of this research has focused on Child Advocacy Center team members. This practice-based survey research addresses that gap. The study examined secondary traumatic stress (STS), burnout, and compassion satisfaction (CS) in interdisciplinary team members (n=36) of one Child Advocacy Center in the southern United States, and explored relationships between CS, STS, and burnout. As assessed by the Secondary Traumatic Stress Scale, 50\% of participants experience Post Traumatic Stress Disorder symptoms due to STS. Based on the Professional Quality of Life Scale, burnout was low and CS was high. Those with higher CS had lower burnout and STS. Positive associations were also found between life stresses in the past year as measured by the Social Readjustment Rating Scale and STS and burnout, but not CS. Practitioners, agency supervisors, and administrators need to be aware of the effects of trauma work, regularly assess for these effects, and provide opportunities for support and debriefing. Schools of social work should consider developing and implementing specialized units on STS and self-care.
\end{abstract}

Keywords: Secondary traumatic stress; burnout; compassion satisfaction; child advocacy centers; child sexual abuse; trauma; PTSD

Freudenberger (1974) was one of the first to explore burnout and did so among staff of the free clinic movement. In the 1980's researchers began to study the rate of burnout in the helping professions and the factors that contributed to it (Davis-Sacks, Jayaratne, \& Chess, 1985; Etzion \& Pines, 1986; Jayaratne \& Chess, 1984; Maslach \& Jackson, 1981). Maslach (1982) defined burnout as "a syndrome of emotional exhaustion, depersonalization, and reduced personal accomplishment that can occur among individuals who do 'people work' of some kind" (p. 3). Burnout is often a consequence of a stressful work environment and workplace characteristics, including few resources and high caseloads (Kahill, 1988). Although the first studies of burnout were in the 1970's and 1980's, it continues to be a focus of study (Anderson, 2000; Hamama, 2012a, 2012b; Kim, 2011; Lizano \& Mor Barak, 2015; Siebert, 2005; Stevens \& Higgins, 2002).

Recent literature has also focused on secondary traumatic stress (STS), vicarious trauma (VT), and compassion fatigue (CF; Baum, 2016; Bride, 2007; Conrad \& KellarGuenther, 2006; Dagan, Ben-Porat, \& Itzhaky, 2016; Schuler, Bessaha, \& Moon, 2016). Although each of these terms has differences in "theoretical origin and symptom foci" (Bride, Radey, \& Figley, 2007, p. 156), they are often used interchangeably to refer to the stress from working with traumatized clients. Although there are subtle differences among

Marlys Staudt, Ph.D. Associate Professor, University of Tennessee, College of Social Work, Knoxville, TN., 37996. Mona Williams-Hayes, Ph.D., LCSW. Clinical Director, Kids First Child Advocacy Center, Lenoir City, TN., 37771.

Copyright @ 2019 Authors, Vol. 19 No. 2 (Fall 2019), 416-429, DOI: 10.18060/22957

(cc) BY

This work is licensed under a Creative Commons Attribution 4.0 International License. 
STS, CF, and VT, according to Stamm (2010), there is "no delineation between them sufficient to say that they are truly different" (p. 9).

Secondary traumatic stress refers to behaviors and emotions occurring from knowing or hearing about a traumatic event experienced by a significant other (Figley, 1995). STS includes the indirect stress experienced by helping professionals who work with traumatized clients. Even though the stress is indirect, the consequent behaviors and emotions are similar to those of posttraumatic stress disorder (PTSD), including hyperarousal, intrusive imagery, and distressful emotions (Bride et al., 2007). In short, indirect or secondary exposure to a traumatic event or events, by hearing about it in a professional or personal relationship, can lead to secondary traumatic stress, and to symptoms of, or full-fledged PTSD. In a sample of licensed social workers in one U.S. state, Bride (2007) found that 70\% reported at least one STS symptom in the past week, and $15.2 \%$ potentially met the criteria for PTSD.

VT differs from STS because of its focus on cognitions, including changes in beliefs, hope, spirituality, worldview, and meaning, which come from caring for those who have experienced trauma (Pearlman \& Saakvitne, 1995; Sabin-Farrell \& Turpin, 2003). Subclinical signs of PTSD may also be present in VT (Baum, 2016). Professionals with VT experience transformation in schemas when one's experiences do not conform to prior worldviews and ways of understanding (Huggard, Stamm, \& Pearlman, 2013). This transformation usually occurs gradually over time.

In contrast, compassion fatigue is the "here and now" perception of trauma work (Huggard et al., 2013, p. 131), including the distress and exhaustion that occur from witnessing the suffering or negative experiences of others (Figley, 1995). Stamm (2010) conceptualized compassion fatigue as consisting of two parts: burnout and STS. CF is the negative aspect of work that contributes to a helper's professional quality of life, which refers to how professionals feel about their work as a helper.

Although burnout may also be present in CF/STS (Bride et al., 2007), the latter can result from a single exposure to a traumatic event, even indirectly, whereas burnout is a process that occurs over time because of job stress (Conrad \& Kellar-Guenther, 2006). Burnout is a broader term than CF or STS, and does not necessarily refer to trauma work. All of these phenomena have negative consequences for helping professionals (low sense of efficacy, hopelessness, etc.), can interfere with building positive relationships with clients, and may result in turnover (Bride \& Kintzle, 2011; Conrad \& Kellar-Guenther, 2006).

Whereas $\mathrm{CF}$ is the negative aspect of professional quality of life, compassion satisfaction (CS) is the positive aspect that contributes to professional quality of life. CS refers to the sense of satisfaction, success, and accomplishment that comes from helping clients (Stamm, 2002, 2005). Silveira and Boyer (2015) found that counselors who worked with youth who were victims of sexual abuse reported hope and optimism resulting from building positive relationships with children and families, and seeing them cope with and manage their adverse circumstances. The reciprocal and intense relationships that result in $\mathrm{CF}$ can also result in CS. Helping professionals can have positive experiences from these relationships, just as the relationship is also a growth experience for clients. 
Professionals who work with physically and sexually abused children are at risk of CF, because they hear stories of harm and abuse that children experience, often from a trusted friend or family member. Studies have reported high rates of CF in child protective service workers (Conrad \& Kellar-Guenther, 2006; Meyers \& Cornille, 2002), and some studies have documented that social workers engaged in child protection work have higher rates of burnout than do social workers in other settings (Maslach, 1982; Sprang, Craig, \& Clark, 2011).

Choi (2011) reported symptoms of STS among social workers who provide services to survivors of family violence or sexual assault. Forensic interviewers with Child Advocacy Centers have also shown signs of STS (Bonach \& Heckert, 2012; Perron \& Hiltz, 2006). Taken together, these findings suggest that helping professionals who work with survivors of child sexual abuse and other family violence are vulnerable to CF. At the same time, CS may protect against the negative effects of CF. Child protective service workers with high CS had lower rates of compassion fatigue and burnout (Conrad \& Kellar-Guenther, 2006). Thomas (2013) also found a negative relationship between CF and CS among clinical social workers, and Meadors, Lamson, Swanson, White, and Sira (2009) reported that pediatric healthcare providers who scored high on CS had lower rates of burnout and STS.

Finally, a professional's level of personal stress and recent losses can influence burnout, CF, and CS (Bonach \& Heckert, 2012; Thomas, 2013). In a sample of oncology social workers, recent personal losses were positively associated with burnout (Simon, Pryce, Roff, \& Klemmack, 2005). Personal distress was positively associated with CF and burnout and negatively associated with CS in a sample of clinical social workers (Thomas, 2013). Bonach and Heckert (2012) found that significant losses in the past year was positively associated with STS in their sample of Child Advocacy Center (CAC) forensic interviewers. They suggested that stress accumulation might make workers more vulnerable to developing STS.

Although Bonach and Heckert (2012) and Perron and Hiltz (2006) studied STS among Child Advocacy Center (CAC) forensic interviewers, other CAC team members, including law enforcement, child protective service workers, and therapists, are also subject to the stresses that occur from providing services to sexually abused and severely physically abused children. Yet, research that has examined the needs of CAC workers is slim (Bonach \& Heckert, 2012). Our study addressed this gap.

This practice-based study examined CF (burnout and STS) among CAC interdisciplinary team members in one geographic region of a Southern state. We also sought to learn whether CF is lower when compassion satisfaction (CS) is higher, as well as whether stressful events occurring within the past year affected CF and CS. The research questions were:

1. What is the level of burnout, STS, and CS among the sample of CAC interdisciplinary team members?

2. Does burnout and STS vary by the level of CS?

3. Is cumulative stress associated with CS, burnout, and STS? 


\section{Method}

\section{Setting}

The research took place in a Child Advocacy Center in a Southeastern US state. The CAC provides assessment and treatment of children and youth identified by the state Department of Children's Services as severely physically and/or sexually abused. The average child served by this CAC is an eight-year-old female who experienced sexual abuse. The CAC's primary treatment modalities are Trauma Focused Cognitive Behavior Therapy and Eye Movement Desensitization and Reprocessing treatment. In addition to assessment and treatment, the CAC provides school-based prevention programs and trainings to professionals involved with child abuse. The CAC provides services to four rural counties. Each county has an interdisciplinary team to coordinate investigations, services, and treatment for children and families. The team consists of professionals from law enforcement, CAC, Department of Children's Services (DCS), juvenile court, and the District Attorney offices.

\section{Procedures}

The Clinical Director of the CAC (the second author of this article) coordinates the interdisciplinary team in each county. She distributed a packet at one of the team meetings in each of the four counties. The packet consisted of a cover letter that contained information about the study and informed consent, as well as the survey (described below). The cover letter and the survey were in a manila envelope, with no names on the envelope or survey. Team members who chose to participate returned the envelope with the completed survey at a designated location. These procedures ensured that the team members would not feel pressure to complete the survey. The clinical director does not exercise supervisory authority over the team participants thus decreasing the chance that they felt obligated to complete the survey. The survey took approximately 15 to 20 minutes to complete.

Those who completed the survey received a \$20 Wal-Mart gift card. Upon return of the survey, participants emailed their name and preferred mailing address to the first author, who mailed the gift card. The Institutional Review Board at the University of Tennessee approved the study procedures.

\section{Measures}

The survey consisted of the Secondary Traumatic Stress Scale (STSS), the Professional Quality of Life Scale (ProQOL), and the Social Readjustment Rating Scale (SRRS), sometimes referred to as the Life Stress Test. Six questions pertained to personal and work demographics.

STSS. Bride (2007) developed the STSS to assess the frequency of STS symptoms among professionals working with traumatized clients. The STSS consists of 17 items, answered on a scale of 1 (never), 2 (rarely), 3 (occasionally), 4 (often), or 5 (very often). Participants rate each item according to how frequently they experienced it in the last seven days. There are three subscales: intrusion (five items), avoidance (seven items), and arousal 
(five items). Item examples from the intrusion subscale are: "reminders of my work with clients upset me" and "I had disturbing dreams about my work with clients." Examples of items on the avoidance subscale are: "I felt emotionally numb" and "I felt discouraged about the future." Item examples from the arousal subscale are: "I had trouble sleeping" and "I was easily annoyed." The potential range of scores for the subscales and total scale are 5 to 25 for the intrusion subscale, 7 to 35 for the avoidance subscale, 5 to 25 for the arousal subscale, and 17 to 85 for the total scale. Higher scores indicate more frequent STS symptoms.

Bride, Robinson, Yegidis, and Figley (2004) reported the alpha for the measure as .93, with subscale alphas ranging from .80 to .87 . The STSS has good construct validity (Bride at al., 2004; Ting, Jacobson, Sanders, Bride, \& Harrington, 2005). The alphas for the present study were .93 for the total scale, .80 for the intrusion subscale, .87 for the avoidance subscale, and .81 for the arousal subscale.

As noted below, one of the subscales of the ProQOL measures STS. We used the STSS in addition to the ProQOL because the STSS provides information about the level of intrusion, avoidance, and arousal. Since we were using the ProQOL to obtain measures of CS and burnout, we decided to also retain the STS subscale.

ProQOL. The ProQOL measures the positive and negative effects of working with clients who have experienced trauma or stressful events (Stamm, 2010). The ProQOL consists of 30 items, answered on a scale of 1 (never), 2 (rarely), 3 (sometimes), 4 (often), or 5 (very often). Participants rate how frequently each item was experienced in the past 30 days. The ProQOL is comprised of three subscales: compassion satisfaction (10 items), burnout (10 items), and secondary traumatic stress (10 items). Examples of items from the compassion satisfaction subscale are: "I like my work" and "I am proud of what I can do to help." Examples from the burnout subscale are: "I feel trapped by my job" and "I feel bogged down by the system."

Item examples from the STS subscale are: "I jump or am startled by unexpected sounds" and "I can't recall important parts of my work with trauma victims." Scores for each subscale are summed (sums can range from 10 to 50). Higher scores indicate higher CS, burnout, or STS.

Stamm (2002) reported alphas of .87 for compassion satisfaction, .72 for burnout, and .80 for secondary traumatic stress. Discriminant validity exists for the subscales, showing each is tapping into a different construct (Stamm, 2005); it is not appropriate to add the subscales to obtain a total score. The alphas for the present study were .91 for compassion satisfaction, .82 for burnout, and .76 for secondary traumatic stress.

SRRS. The SRRS measures the cumulative stress of individuals. Participants check which of 43 life events have occurred over the past 12 months. Each event has an impact score, ranging from 100 for death of a spouse to 11 for minor violations of the law. Other events are personal injury or illness, marriage, death of a close friend, and trouble with the boss. The impact scores are added for a total score. This measure has been long in use, and researchers reported these life events correlated with health changes and medical visits (Rahe, Biersner, Ryman, \& Arthur, 1972; Rahe, Mahan, \& Arthur, 1970). 


\section{Analysis}

We used the three approaches described by Bride (2007) to analyze the STSS scores. First, we compared scores of the present sample to the normative means and percentiles for each subscale and the total score presented by Bride (2007). Using percentiles from the normative sample, participants were classified as experiencing little or no, mild, moderate, high or severe STS, and likewise for the subscales of intrusion, avoidance, and arousal.

A second approach is to consider those scoring at 38 or higher on the STSS as potentially having PTSD due to STS. The third approach to scoring the STSS is to use an algorithm whereby if at least one item on the intrusion subscale is endorsed, at least three items on the avoidance subscale are endorsed, and at least two items on the arousal subscale are endorsed, to then consider that PTSD may be present due to STS. An item that is marked occasionally, often, or very often is considered an endorsed item.

Based on the scoring protocol for the ProQOL (Stamm, 2010), we reversed scored the designated items and then summed the items of each subscale. The subscale sum was then interpreted as low, average, or high on that concept (compassion satisfaction, burnout, and secondary traumatic stress). For the SRRS we assigned impact scores to each item and added them for a total impact score.

We used SPSS 23 for the analysis. We calculated frequencies and means to describe the sample and the scores on the measures. We conducted bivariate Pearson correlations to examine the relationships among the measures, specifically whether there was an inverse relationship between CS and burnout and STS, and whether there were significant relationships between the SRRS impact score and STS, burnout, and CS. Given the small sample size, we used an alpha of .10.

\section{Results}

\section{Participants}

Surveys were distributed to 50 potential respondents. Thirty-six returned the survey, for a response rate of $72 \%$. Of the 36 participants, $26(72.2 \%)$ were female. The mean age was 40.8 ( $\mathrm{SD}=12.6$ ), ranging from 21 to 76 . All participants were Caucasian, consistent with the ethnic/racial makeup of the rural area. Twelve (33.3\%) of the participants were from DCS, ten (27.8\%) were from CAC, and nine (25\%) were from law enforcement. The remainder were from juvenile court, from the DA's office/attorneys, or medical personnel. Participants had a mean of 11.8 years $(\mathrm{SD}=11.5)$ employed in their profession and a mean of eight years $(\mathrm{SD}=5.8)$ working with abused children.

\section{Research Question One: What is the level of burnout, STS, and CS among the sample of CAC interdisciplinary team members?}

The mean ProQOL CS subscale score for the 36 respondents was 39.4 ( $\mathrm{SD}=5.8$ ). This is in the 'moderate' range of CS (Stamm, 2010). The mean ProQOL burnout subscale score was $22.8(\mathrm{SD}=6)$, which is in the 'low' range of burnout. Table 1 shows the number of 
participants who scored low, moderate, or high on the ProQOL subscales. As can be seen, all of the participants scored moderate or high on CS and low or moderate on burnout.

There was evidence that suggested concerning rates of STS. The mean ProQOL STS subscale score was $22.8(\mathrm{SD}=5.3)$, in the moderate range. Based on the ProQOL STS subscale, $44 \%(\mathrm{n}=16)$ scored low in secondary traumatic stress and the remainder $(56 \%$, $\mathrm{n}=20$ ) scored in the moderate range (see Table 1).

Table 1. Distribution of Low, Moderate, or High Scoring on the ProQOL Subscales

\begin{tabular}{l|r|r|r|c}
\hline & \multicolumn{2}{|c|}{ Number and Frequency } & \\
\cline { 2 - 4 } Subscale & Low & Moderate & High & All \\
\hline CS & - & $21(60 \%)$ & $14(40 \%)$ & 35 \\
Burnout & $15(44 \%)$ & $19(56 \%)$ & - & 34 \\
STS & $16(44 \%)$ & $20(56 \%)$ & - & 36 \\
\hline
\end{tabular}

Table 2 shows how the sample scored on the STSS. The classification into the five categories are based on the normative means and percentiles provided by Bride (2007). Seventeen respondents (50\% of those with no missing data) had moderate, high or severe STS, based on the total score, with six participants scoring at the severe level of STS. When looking at those who scored at the moderate, high, or severe level on the subscales, Table 2 shows that $41 \%$ were in this range on the intrusion subscale, $39 \%$ on the avoidance subscale, and $52 \%$ on the arousal subscale.

Table 2. Distribution of Little/No, Mild, Moderate, High, or Severe Scoring for Total STSS and the Intrusion, Avoidance, and Arousal Subscales

\begin{tabular}{|c|c|c|c|c|c|c|}
\hline & \multicolumn{5}{|c|}{ Number and Frequency } & \multirow[b]{2}{*}{ All } \\
\hline & Little/No & Mild & Moderate & High & Severe & \\
\hline Intru & $5(14 \%)$ & $15(44 \%)$ & $1(.03 \%)$ & $6(17 \%)$ & $8(24 \%)$ & 35 \\
\hline Avoidance & $18(50 \%)$ & $4(11 \%)$ & $10(28 \%)$ & & $4(11 \%)$ & 36 \\
\hline Arous & $6(17 \%)$ & $11(31 \%)$ & $10(29 \%)$ & $3(9 \%)$ & $5(14 \%)$ & 35 \\
\hline Total & $7(21 \%)$ & $10(29 \%)$ & $8(23 \%)$ & $3(9 \%)$ & $6(18 \%)$ & 34 \\
\hline
\end{tabular}

The second way to interpret STSS scores is to consider those scoring 38 or higher as possibly having PTSD due to STS. A score of 38 on the STSS is at the lower tail of the moderate range. Based on this approach, 17 (50\%) of 34 participants could possibly have PTSD due to STS. The third approach uses the algorithm described above. In the current sample, after applying the algorithm, 13 participants (38\%) may have PTSD.

\section{Research Question 2: Does burnout and STS vary by the level of CS?}

Table 3 shows the correlations between the CS subscale of the ProQOL, the burnout subscale of the ProQOL, the STS subscale of the ProQOL, and the STSS total score and intrusion, avoidance, and arousal subscales. Participants with higher CS had statistically significant lower burnout and STS than did those with lower CS. The relationship between burnout and CS was stronger than the relationship between the STS measures and CS. 
Table 3. Pearson Correlations between Compassion

Satisfaction and ProQOL, STSS subscales

\begin{tabular}{l|l|l|l}
\hline ProQOL and STSS & \multicolumn{3}{|c}{ Compassion Satisfaction } \\
\cline { 2 - 4 } Subscales & $n$ & $r$ & $p$ \\
\hline ProQOL Burnout & 33 & -0.646 & $0.001^{*}$ \\
ProQOL STS & 35 & -0.308 & 0.072 \\
STSS Intrusion & 34 & -0.322 & 0.063 \\
STSS Avoidance & 35 & -0.340 & $0.045^{*}$ \\
STSS Arousal & 34 & -0.287 & 0.099 \\
STSS Total & 33 & -0.390 & $0.025^{*}$ \\
\hline *p $<.05, * * \mathrm{p}<.01$ & & & \\
\hline
\end{tabular}

\section{Research Question 3: Is cumulative stress associated with CS, burnout, and STS?}

Table 4 shows that statistically significant positive relationships were found between SRRS total impact score and the ProQOL burnout subscale, the ProQOL STS subscale, the STSS total scale, and the three STSS subscales. Thus, participants who experienced more stressful events had higher burnout and STS symptoms. There was not a significant relationship between the SRRS and CS.

Table 4. Pearson Correlations of SRRS with CS, Burnout, and STS

\begin{tabular}{l|l:l:l}
\hline & \multicolumn{2}{|c}{ SRSS Total Impact Score } \\
Title & $n$ & $r$ & $p$ \\
\hline ProQOL CS & 35 & -0.086 & 0.624 \\
ProQOL Burnout & 34 & 0.388 & $0.023^{*}$ \\
ProQOL STS & 36 & 0.520 & $0.001^{* *}$ \\
STSS Intrusion & 35 & 0.415 & $0.013^{*}$ \\
STSS Avoidance & 36 & 0.416 & $0.012^{*}$ \\
STSS Arousal & 35 & 0.399 & $0.018^{*}$ \\
STSS Total & 34 & 0.420 & $0.014^{*}$ \\
\hline *p<.05, **p<.01 & & & \\
\hline
\end{tabular}

\section{Discussion}

The purpose of this study was to examine CS, STS, and burnout in a sample of interdisciplinary CAC team members. Prior to discussing the implications, the substantial study limitations are noted. A primary limitation of the study was the small and homogenous sample. The study took place in one rural geographic region of one state in the U.S., and the small sample was composed primarily of female Caucasians who worked on a CAC interdisciplinary team. The lack of diversity of the sample limits generalizing the findings to helping professionals in other settings. The small sample size limits the statistical analyses to bivariate correlations. Although participants included members of different disciplines, the sample size did not permit us to examine whether there were differences in burnout, STS, and CS by discipline. This is worthy of future research with larger sample sizes. 
In relation to the first research question, we found that up to $50 \%$ of the participants may be experiencing PTSD symptomsdue to STS. The mean total STSS score in the sample was 38.7 ( $\mathrm{SD}=12.45$ ), higher than the means found in other study samples. Choi (2011) reported a mean on the STSS of 32.07 in a sample of social workers who provided services to survivors of family violence or sexual assault. Among CAC forensic interviewers STSS means of 36.69 and 34.17 have been reported (Bonach \& Heckert, 2012; Perron \& Hiltz, 2006).

Findings from the ProQOL STS subscale provide a somewhat more positive picture, as none of the participants fell in the high range for STS or burnout. Still, over half were in the moderate range for burnout and STS. Over half were in the moderate range of CS, and the remainder were high in CS. This is an overall positive profile, suggesting that the participants feel their work is important, but that they may still have some symptoms of STS that should be addressed (Stamm, 2010).

Findings from the second research question showed that those with higher CS had lower burnout and STS. These findings are consistent with other studies showing thatthose with higher compassion satisfaction had lower burnout and secondary traumatic stress (Conrad \& Kellar-Guenther, 2006; Stamm, 2002).

The findings related to the third research question were consistent with the notion that personal experiences of the helping professional influence burnout and STS (Siebert, 2005). Our findings showed that recent stress events were positively associated with burnout and STS. The non-significant relationship between CS and recent life stressful events is noteworthy. Studies with larger samples should examine whether personal life events in professional helpers influence their CS. Professionals' own life events may be so stressful that they interfere with their work with clients. Conversely, one's own experiences may increase compassion for others. Of course, there is also the type and timing of events to consider.

There are several possible reasons why the STSS had different findings in relation to STS than did the STS subscale of the ProQOL. First, participants rated the STSS items as to how frequently each was experienced in the past seven days, whereas they rated the STS subscale items according to how frequently each was experienced in the past 30 days. Second, there may have been an ordering effect in the survey as the STSS was the first instrument that participants completed, followed by the ProQOL. Third, the alpha for the STS subscale in the current study was lower than that reported by Stamm and lower than the current study's alphas for the STSS total score and subscales. More work on examining the concordance of various STS scales would be useful.

Craig and Sprang (2010) found that professionals who worked with victims of trauma and reported the use of evidence-based practices had lower levels of burnout and higher levels of compassion satisfaction. The CAC in this study uses Trauma Focused Cognitive Behavior Therapy and Eye Movement Desensitization and Reprocessing, evidence-based interventions for trauma, including sexual abuse. This might partially explain the low level of burnout and high level of compassion satisfaction among the study participants. 
We did not include a measure of peer or supervisory support. Studies that include measures of peer or supervisory support would shed light on whether and how social support moderates the effect of trauma work.

Study findings have implications for social work practitioners and for the curricula of professional schools. Social work students and those already in the field should receive information about the potential impact of trauma work for themselves. This includes knowing what STS signs to look for as well as the need to incorporate self-care into their lives. Bloomquist et al. (2015) found that MSW practitioners infrequently engage in selfcare activities and that MSW programs and employing agencies do not provide instruction on self-care activities. Yet, these authors also found that study participants who practiced professional and emotional self-care had higher CS, which emphasizes its relevance to professional practice. Educators might consider developing a specialized unit on STS and self-care and integrating it into required course work. Thus, STS would begin to become a real and relevant issue that is present in working with clients who have experienced trauma. Students will understand that they will need to address it in their future professional work and will learn self-care strategies to do so. Supervisors and agencies need to provide opportunities for support to alleviate the effects of trauma work. Prior to doing so, however, they need to understand the effects of trauma work. Thus, it may be helpful to implement workshops for professionals, especially supervisors and agency administrators, which focus on the effects of working with traumatized clients. Bonach and Heckert (2012) noted that traditional support that encourages collegiality and team building might not be adequate and that it is important to provide "clinical" debriefings and proactive mental health care for professionals who work with clients with trauma. Agencies should consider building in regular opportunities for support, debriefings, and even breaks from the usual work routine to provide workers some time to engage in self-care activities. We need to learn more about interventions for professionals with STS. It may be especially important to examine interventions that can take place in the work setting as a normal routine for workers who regularly work with trauma.

There are over 900 CAC's in the United States. Researchers should conduct more studies to understand the unique needs of these professionals who are daily on the frontline, providing specialized services to severely physically and sexually abused children. A recommendation is that future research use larger and more diverse samples than the current study. Examining differences in STS, burnout, and CS by discipline and education level would be helpful It would also be beneficial if future studies asked respondents if they have had such training, maybe even where they received the training, for example, in college or as continuing education. Having such training could be included as a covariate in future studies to assess the effectiveness of such training. Our study took place in a rural region. Future studies should include urban regions and test for differences in CF and CS across various geographic regions. Research should include organizational variables as well as personal characteristics of the professionals to clarify who is most at risk of STS and burnout and what factors mitigate the risk. Examples of personal characteristics that could be included are job satisfaction, spirituality, social support, trauma, and adverse childhood experiences. Qualitative studies with in-depth personal interviews or focus groups would also be helpful to hear in the helpers' own words how they experience STS, 
their current knowledge of STS, and the coping strategies they use to deal with the effects of trauma work.

Although studies with larger sample sizes are necessary to increase generalizable knowledge about the effects of trauma work, the findings of this study begin to shed light on STS, burnout, and CS among CAC team members. At the same time, smaller practicebased studies, such as the one reported in this article, can influence practices and policies within agencies, while informing future research. Much more remains to be known about specialized CAC services that aim to meet the needs of some of the most severely abused children and their families, including the level of STS and burnout among various team members, and the efforts they and their organizations use to address the effects of trauma work.

\section{References}

Anderson, D. (2000). Coping strategies and burnout among veteran child protection workers. Child Abuse and Neglect, 24(6), 839-848. doi: https://doi.org/10.1016/s0145-2134(00)00143-5

Baum, N. (2016). Secondary traumatization in mental health professionals: A systematic review of gender findings. Trauma, Violence, and Abuse, 17(2), 221-235. doi: https://doi.org/10.1177/1524838015584357

Bloomquist, K. R., Wood, L., Friedmeyer-Trainor, K., \& Kim, H-W. (2015). Self-care and professional quality of life: Predictive factors among MSW practitioners. Advances in Social Work, 16(2), 292-311. doi: https://doi.org/10.18060/18760

Bonach, K., \& Heckert A. (2012). Predictors of secondary traumatic stress among Children's Advocacy Center forensic interviewers. Journal of Child Sexual Abuse, 21, 295-314. doi: https://doi.org/10.1080/10538712.2012.647263

Bride, B. E. (2007). Prevalence of secondary traumatic stress among social workers. Social Work, 52(1), 63-70. doi: https://doi.org/10.1093/sw/52.1.63

Bride, B. E., \& Kintzle, S. (2011). Secondary traumatic stress, job satisfaction, and occupational commitment in substance abuse counselors. Traumatology, 17(1), 2228. doi: https://doi.org/10.1177/1534765610395617

Bride, B. E., Radey, M., \& Figley, C. R. (2007). Measuring compassion fatigue. Clinical Social Work Journal, 35, 155-163. doi: https://doi.org/10.1007/s10615-007-0091-7

Bride, B. E., Robinson, M. M., Yegidis, B., \& Figley, C. R. (2004). Development and validation of the Secondary Traumatic Stress Scale. Research on Social Work Practice, 14(1), 27-35. doi: https://doi.org/10.1177/1049731503254106

Choi, G. Y. (2011). Organizational impacts on secondary traumatic stress of social workers assisting family violence or sexual assault survivors. Administration in Social Work, 35(3), 225-242. doi: https://doi.org/10.1080/03643107.2011.575333 
Conrad, D., \& Kellar-Guenther, Y. (2006). Compassion fatigue, burnout, and compassion satisfaction among Colorado child protection workers. Child Abuse and Neglect, 30, 1071-1080. doi: https://doi.org/10.1016/j.chiabu.2006.03.009

Craig, C. D., \& Sprang, G. (2010). Compassion satisfaction, compassion fatigue, and burnout in a national sample of trauma treatment therapists. Anxiety, Stress, and Coping, 23(3), 319-339. doi: https://doi.org/10.1080/10615800903085818

Dagan, S. W., Ben-Porat, A., \& Itzhaky, H. (2016). Child protection workers dealing with child abuse: The contribution of personal, social and organizational resources to secondary traumatization. Child Abuse and Neglect, 51, 203-211. doi: https://doi.org/10.1016/j.chiabu.2015.10.008

Davis-Sacks, M., Jayaratne, S., \& Chess, W. (1985). A comparison of the effects of social support on the incidence of burnout. Social Work, 30, 240-244. doi: https://doi.org/10.1093/sw/30.3.240

Etzion, D., \& Pines, A. (1986). Sex and culture in burnout and coping among human service professionals: A social psychological perspective. Journal of Cross-Cultural Psychology, 17, 191-209. doi: https://doi.org/10.1177/0022002186017002004

Figley, C. R. (1995). Compassion fatigue as secondary traumatic stress disorder: An overview. In C. R. Figley (Ed.), Compassion fatigue: Coping with traumatic stress disorder (pp. 1-20). New York, NY: Brunner/Mazel. doi: https://doi.org/10.4324/9780203777381

Freudenberger, H. J. (1974). Staff burn-out. Journal of Social Issues, 30, 159-165. doi: https://doi.org/10.1111/j.1540-4560.1974.tb00706.x

Hamama, L. (2012a). Differences between children's social workers and adults' social workers on sense of burnout, work conditions, and organizational social support. British Journal of Social Work, 42, 1333-1353. doi: https://doi.org/10.1093/bjsw/bcr135

Hamama, L. (2012b). Burnout in social workers treating children as related to demographic characteristics, work environment, and social support. Social Work Research, 36(2), 113-125. doi: https://doi.org/10.1093/swr/svs003

Huggard, P., Stamm, B. H., \& Pearlman, L. A. (2013). Compassion satisfaction, compassion fatigue, and vicarious traumatization. In C. R. Figley, P. Huggard, \& C. E. Rees (Eds.), First do no self-harm: Understanding and promoting physician stress resilience (pp. 127-145). NY: Oxford. doi: https://doi.org/10.1093/acprof:oso/9780195383263.003.0007

Jayartne, S., \& Chess, W. A. (1984). Job satisfaction, burnout, and turnover: A national study. Social Work, 29, 448-453. doi: https://doi.org/10.1093/sw/29.5.448

Kahill, S. (1988). Interventions for burnout in the helping professions: A review of the empirical evidence. Canadian Journal of Counselling Review, 22(3), 162-169. 
Kim, H. (2011). Job conditions, unmet expectations, and burnout in public child welfare workers: How different from other social workers? Children and Youth Services Review, 33, 358-367. doi: https://doi.org/10.1016/j.childyouth.2010.10.001

Lizano, E. L., \& Mor Barak, M. (2015). Job burnout and affective well-being: A longitudinal study of burnout and job satisfaction among public child welfare workers. Children and Youth Services Review, 55, 18-28. doi: https://doi.org/10.1016/j.childyouth.2015.05.005

Maslach, C. (1982). Burnout-The cost of caring. Englewood Cliffs, NJ: Prentice-Hall.

Maslach, C., \& Jackson, S. E. (1981). The measurement of experienced burnout. Journal of Occupational Behavior, 2, 99-113.

Meadors, P., Lamson, A., Swanson, M., White, M., \& Sira, N. (2009). Secondary traumatization in pediatric healthcare providers: Compassion fatigue, burnout, and secondary traumatic stress. Omega, 60(2), 103-128. doi: https://doi.org/10.2190/om.60.2.a

Meyers, T. W., \& Cornille, T. A. (2002). The trauma of working with traumatized children. In C. R. Figley (Ed.), Treating compassion fatigue (pp. 39-55). New York: Brunner-Routledge.

Pearlman, L. A., \& Saakvitne, K. W. (1995). Trauma and the therapist: Countertransference and vicarious traumatization in psychotherapy with incest survivors. NY: W. W. Norton \& Company. doi: https://doi.org/10.1080/00029157.1996.10403354

Perron, B. E., \& Hiltz, B. S. (2006). Burnout and secondary trauma among forensic interviewers of abused children. Child and Adolescent Social Work Journal, 23(2), 216-234. doi: https://doi.org/10.1007/s10560-005-0044-3

Rahe, R. H., Biersner, R. J., Ryman, D. H., \& Arthur, R. J. (1972). Psychosocial predictors of illness behavior and failure in stressful training. Journal of Health and Social Behavior, 13(4), 393-397. doi: https://doi.org/10.2307/2136831

Rahe, R. H., Mahan, J. L., \& Arthur, R. J. (1970). Prediction of near-future health change from subjects' preceding life changes. Journal of Psychosomatic Research, 14, 401406. doi: https://doi.org/10.1016/0022-3999(70)90008-5

Sabin-Farrell, R., \& Turpin, G. (2003). Vicarious traumatization: Implications for the mental health of health workers? Clinical Psychology Review, 23, 449-480. doi: https://doi.org/10.1016/s0272-7358(03)00030-8

Schuler, B. R., Bessaha, M. L., \& Moon, C. A. (2016). Addressing secondary traumatic stress in the human services: A comparison of public and private sectors. Human Service Organizations: Management, Leadership, and Governance, 40(2), 94-106. doi: https://doi.org/10.1080/23303131.2015.1124060 
Siebert, D. C. (2005). Personal and occupational factors in burnout among practicing social workers: Implications for researchers, practitioners, and managers. Journal of Social Service Research, 32(2), 25-43. doi: https://doi.org/10.1300/j079v32n02_02

Silveira, F. S., \& Boyer, W. (2015). Vicarious resilience in counselors of child and youth victims of interpersonal trauma. Qualitative Health Research, 25(4), 513-526. doi: https://doi.org/10.1177/1049732314552284

Simon, C. E., Pryce, J. G., Roff, L. L., \& Klemmack, D. (2006). Secondary traumatic stress and oncology social work. Journal of Psychosocial Oncology, 23(4), 1-14. doi: https://doi.org/10.1300/j077v23n04_01

Sprang, G., Craig, C., \& Clark, J. (2011). Secondary traumatic stress and burnout in child welfare workers: A comparative analysis of occupational distress across professional groups. Child Welfare, 90(6), 149-168.

Stamm, B. H. (2002). Measuring compassion satisfaction as well as fatigue. Developmental history of the compassion satisfaction and fatigue test. In C. R. Figley (Ed.), Treating compassion fatigue (pp. 107-119). New York: Brunner-Routledge. doi: https://doi.org/10.1037/t66725-000

Stamm, B. H. (2005). The Professional Quality of Life Scale: Compassion satisfaction, burnout, and compassion fatigue/secondary traumatic scales. Lutherville, MD: Sidran Press.

Stamm, B. H. (2010). The Concise ProQOL Manual (2nd ed.). Pocatello, ID: ProQOL.org.

Stevens, M., \& Higgins, D. (2002). The influence of risk and protective factors on burnout experienced by those who work with maltreated children. Child Abuse Review, 11, 313-331. doi: https://doi.org/10.1002/car.754

Thomas, J. (2013). Association of personal distress with burnout, compassion fatigue, and compassion satisfaction among clinical social workers. Journal of Social Service Research, 39(3), 365-379. doi: https://doi.org/10.1080/01488376.2013.771596

Ting, L., Jacobson, J. M., Sanders, S., Bride, B. E., \& Harrington, D. (2005). The Secondary Traumatic Stress Scale (STSS): Confirmatory factor analyses with a national sample of mental health social workers. Journal of Human Behavior in the Social Environment, 11, 177-194. doi: https://doi.org/10.1300/j137v11n03 09

Author note: Address correspondence to Dr. Marlys Staudt, 311 Henson Hall, College of Social Work, University of Tennessee, Knoxville, TN, 37996. E-mail: mstaudt@utk.edu 